\title{
Retailer's inventory policy for deteriorating items under partial trade credit policy
}

\author{
Alok Kumar $^{\mathbf{a}}$, K. K. Kaanodiaya ${ }^{\mathrm{b}}$ and R. R. Pachauri ${ }^{\mathbf{*}}$ \\ ${ }^{a}$ Institute of Engineering and Technology, Khandhari, Agra, India \\ ${ }^{b}$ Department of Mathematics, BSA College, Mathura, India

\begin{tabular}{|c|c|}
\hline A R T I C L E I N F O & A B S T R A C T \\
\hline $\begin{array}{l}\text { Article history: } \\
\text { Received } 15 \text { September } 2010 \\
\text { Received in revised form } \\
4 \text { December } 2010 \\
\text { Accepted } 5 \text { December } 2010 \\
\text { Available online } \\
5 \text { December } 2010 \\
\text { Keywords: } \\
\text { Inventory } \\
\text { EOQ }\end{array}$ & $\begin{array}{l}\text { This paper proposes a mathematical model for retailer's optimal inventory policy for } \\
\text { deteriorating items under the conditions of permissible delay in payment in supply chain } \\
\text { coordination. In this paper, supplier offers full trade credit to his/her retailer and the retailer, in } \\
\text { turn, provides the partial trade credit to his/her customer. This research article helps the retailer } \\
\text { determine the optimal cost, more accurately. The primary objective is to minimize the retailer's } \\
\text { cost and to determine the optimal inventory policy for retailer. The results of this article } \\
\text { generalize some already published results by incorporating deterioration on inventory items. } \\
\text { We use some numerical examples to analyze the effects of various parameters on retailer's } \\
\text { inventory policy. }\end{array}$ \\
\hline
\end{tabular}

Inventory

Partial trade credit

Deterioration

Supply chain

\section{Introduction}

Worldwide globalization, technology innovation and changing workforce reveal that the supplier considers business models to stimulate demand of products. In general, the suppliers adopt a business strategy by offering a permissible delay of payment of purchasing goods by customer. In this credit policy, the supplier does not charge any interest if the payment is made before credit period. However, if the payment is paid beyond the predefined period, a high interest rate is charged.

Goyal (1985) is believed to be the first who developed the economic order quantity (EOQ) model under the conditions of permissible delay in payments. Davis and Gaither (1985) presented EOQ model when supplier offers one time opportunity to delay the payments of order in case an order for additional units is placed. Shah et al. (1988) studied the same model incorporating shortages. Mondal and Phaujdar (1989c) extended this issue by considering the interest earned from the sales revenue.

* Corresponding author. Tel: +919917785641

E-mail: rrpachauri@gmail.com (R R Pachauri)

(C) 2011 Growing Science Ltd. All rights reserved. doi: 10.5267/j.ijiec.2010.08.001 
Shah (1993a, b) also developed EOQ models for perishable items where delay in payment is permissible. Shah and Sreehari (1996) presented an extended issue of EOQ model where the delay in payment is permitted and the capacity of own warehouse is limited. Other papers related to this area are Chang and Dye (2002), Chang et al. (2001), Chen and Chung (1999), Chung (1998a, b) Jamal et al. (2000), Sarker et al. (2000a), Salameh et al. (2003), and Chung and Huang (2003), Chung et al. (2005), Chung and Liao (2006), Huang (2007) and Liao and Chung (2009).

In above models, the supplier adopts a business strategy of permissible delay period in paying the purchasing cost to attract more customers. The retailer takes the benefit of trade credit and sells the product and earns the interest by putting generated revenue in an interest bearing account. They implicitly assumed that the buyer would pay the supplier as soon as he/she receives the items. As mentioned earlier, supplier only offers a trade credit to the retailer but retailer does not provide any trade credit to his/her customer which means we deal with one level of trade credit. However, in many real-world cases, this condition does not hold. Recently, Huang (2003) modified this assumption by assuming that the retailer will also adopt the trade credit policy to stimulate his/her customer demand to develop retailer replenishment model and this method is called two level of trade credit policy. Deterioration is defined as decay or damage on the value of inventories that occurs during the time such that the inventory item cannot be used for its original purpose. During the past two decades, there have been some studies on inventory problems in many case studies such as volatile liquid, radioactive materials, agricultural products, medicine, blood, fashion goods and electronic components, etc. Ghare and Schrader (1963) were the two earliest researchers who considered ongoing deterioration of inventory with constant demand. Covert and Philips (1973) used a variable deterioration rate of two parameter Weibull distribution to formulate a model with the assumptions of a constant demand and no shortages. Shah and Jaiswal (1977) and Aggrawal (1978) presented and reestablished an order level inventory model with a constant rate of deterioration, respectively. There are also many other cases where inventory problem has been investigated (Elsayed \& Teresi, 1983; Dave \& Patel, 1981; Sachan, 1984; Hariga, 1996, Teng et al., 1999; Yang et al., 2001; Teng \& Yang, 2004). Recently, Giri and Chakraborty (2010) developed a single-vendor and single-buyer deteriorating inventory model with stock-dependent demand. Yang et al. (2010) proposed a partial backlogging inventory lot-size model for deteriorating items with stock-dependent demand. Abdul and Murata (2011) presented an inventory model for deteriorating items with ramp type demand and unknown time. Many research paper related to the inventory policy under deterioration and permissible delay in payments can be found in Mondal and Phaujdar (1989b), Aggrawal and Jaggi (1995), Hwang and Shinn (1997), Chung and Liao (2004), Jamal et al. (1997), Sarker et al. (2000b ), Chang and Dye (2001), Chu et al. (1998), Chung (2000), Liao et al. (2000), Ouyang et al. (2005) and their references. Recently, Shah and Mishra (2010) analyzed an EOQ model for deteriorating items and trade credit when demand is stock-dependent. Jaggi et al. (2010) developed EOQ model for deteriorating items with imperfect quality under permissible delay in payment. This paper extends Huang and Hsu (2008) model in the light of deteriorating items. In this paper, we develop retailer's optimal ordering policies for deteriorating items in supply chain coordination. Here, supplier offers full trade credit period to his/her retailer but retailer offers just partial trade credit period to his/her customers. The basic objective of this paper is cost minimization for retailer.

\section{Assumptions and notations}

\subsection{Assumptions}

For convenience, most assumptions and notations throughout of this paper used from Huang and Hsu's (2008) model.

1) The demand rate $D$ is deterministic and constant with time.

2) Lead time is zero and shortages are not allowed. 
3) Replenishments are instantaneous.

4) Time horizon is infinite.

5) The supplier provides the full trade credit to the retailer where the cycle time $(T)$ is greater than or equal to the retailer's credit period $(M)$ offered by the supplier. Then, the retailer settles the account at $T=M$. The retailer pays for the product sold and keeps his/her profit, and starts paying interest on unsold items at rate $I_{k}$. When the cycle time $(T)$ is less than or equal to the retailer's credit period $(M)$, the retailer settles the account at $T=M$. Therefore, the retailer does not have to pay any interest charges.

6) The retailer also, in turn, provides the partial trade credit period to his/her customer and the customer would make a partial payment when the remaining items are sold. At the end of credit period, the customers pay off the remaining balance. Therefore, the retailer can accumulate revenue and earn interest with rate $I e$.

7) For deteriorating items, a constant fraction $\theta$ of the on-hand inventory deteriorates per unit of time $(0 \leq \theta<1)$. The value of $\theta$ is small compared to those of other model parameters. Deteriorated inventory items are neither repairable nor replaceable during the planning period.

\subsection{Notations}

1) $D$ demand rate per year

2) $A$ ordering cost per order

3) $c$ unit purchasing price

4) $s$ unit selling price, $s \geq c$

5) $h$ the inventory holding cost per year excluding interest charges

6) $\alpha$ customer's fraction of total amount owed payable at the time of placing an order offered by the retailer, $0 \leq \alpha \leq 1$

7) Ie interest earned per \$ per year

8) $I_{k}$ interest charged per $\$$ invested in stocks per year by the supplier

9) $M$ trade credit period of retailer's offered by the supplier in years

10) $N$ trade credit period of customer's offered by the retailer in years

11) $T$ cycle time in years

12) $T R C(T)$ the total inventory cost per time unit, which is a function of $T$

13) $T^{*}$ optimal cycle time of $\operatorname{TRC}(T)$

14) $Q^{*}$ optimal order quantity

15) $\theta$ the constant deterioration rate, where $0<\theta<1$

16) $Q(t)$ the inventory level at any instant of time $t, 0 \leq t \leq T$ 


\section{Model formulation and convexity}

The level of demand $Q(t)$ gradually decreases mainly to meet demands and partly due to deterioration. Hence, the change of inventory level with respect to time can be described by the following differential equation:

$\frac{d Q(t)}{d t}+\theta Q(t)=-D, \quad 0<t \leq T$

with the boundary conditions $Q(0)=Q, Q(T)=0$. Consequently, the solution of Eq. (1) is given by

$Q(t)=\frac{D}{\theta}\left(e^{\theta(T-t)}-1\right), \quad 0<t \leq T$

and the order quantity is

$Q=\frac{D}{\theta}\left(e^{\theta T}-1\right)$

Total demand during one cycle is $D T$. Therefore, the number of deteriorating items during a replenishment cycle is as follows,

$Q-D T$.

The total relevant cost per year consists of the following components:

(a) Annual ordering cost (OC)

$$
=\frac{A}{T}
$$

Annual inventory holding cost (excluding interest charges) (IHC)

$$
=\frac{h}{T} \int_{0}^{T} Q(t) d t=\frac{h D}{\theta^{2} T}\left(e^{\theta T}-\theta T-1\right) .
$$

Annual cost of deteriorated units (DC)

$$
=\frac{C(Q-D T)}{T}=\frac{c D}{\theta T}\left(e^{\theta T}-\theta T-1\right) .
$$

Case $1 \mathrm{M} \geq \mathrm{N}$

Sub case 1. $M \leq T$ (See in Fig. 1)

In this paper, the sales revenue is utilized to earn interest $I e$ during the period of $(N, M)$ when the account is settled, the items which are still in inventory have to be financed with annual rate $I_{k}$. Therefore, the annual interest payable is as shown in Fig. 1.

$I C_{1}=\frac{c I_{k}}{T} \int_{M}^{T} Q(t) d t=\frac{c D I_{k}}{\theta^{2} T}\left[e^{\theta(T-M)}-\theta(T-M)-1\right]$.

Retailers sell products and deposit the revenue into an account during period $(0, N)$, but getting partial payment at time $N$. Therefore, sales revenue is accumulated from period $(0, N)$ to $(N, M)$ and interest earned in this part is sIe. The annual interest earned is as follows,

$I E_{1}=\frac{s I e}{T}\left[\int_{0}^{N} \alpha D t d t+\int_{N}^{M} D t d t\right]=\frac{D s I e}{2 T}\left[M^{2}-N^{2}(1-\alpha)\right]$

$T R C_{1}=O C+I H C+D C+I C-I E$. 


$$
\begin{aligned}
T R C_{1}=\frac{A}{T}+ & \frac{D(c \theta+h)}{\theta^{2} T}\left(e^{\theta T}-\theta T-1\right)+\frac{c D I_{k}}{\theta^{2} T}\left[e^{\theta(T-M)}-\theta(T-M)-1\right] \\
& -\frac{D S I e}{2 T}\left[M^{2}-N^{2}(1-\alpha)\right] .
\end{aligned}
$$

The optimum value of $T=T_{1}$ is the solution of equation. The value of $\theta$ is sufficiently small. Therefore, using exponential series $e^{\theta T} \approx 1+\theta T+\frac{(\theta T)^{2}}{2}$, as $\theta T$ is small (ignoring $\theta^{2}$ and powers), we get

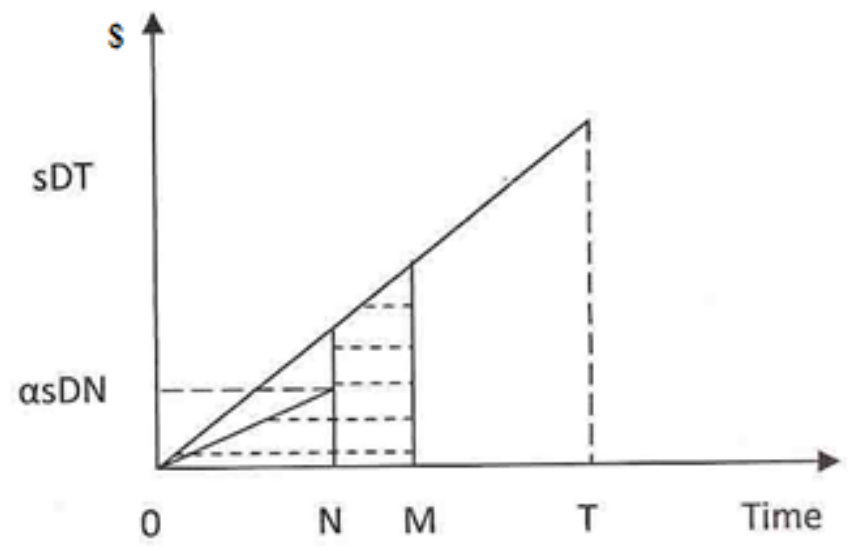

Fig. 1. The total accumulation of interest earned when $M \leq T$.

$\frac{d T R C_{1}(T)}{d T}=-\frac{A}{T^{2}}+\frac{D(c \theta+h)}{2}+\frac{c D I_{k}}{2}-\frac{c D M^{2} I_{k}}{2 T^{2}}+\frac{D s I e}{2 T^{2}}\left[M^{2}-N^{2}(1-\alpha)\right]$,

$T=T_{1}$ minimizes total $\operatorname{cost} ; T R C_{1}(T)$ is provided by the following,

$\frac{d^{2} T R C_{1}(T)}{d T^{2}}=\frac{2 A}{T^{3}}+\frac{c D M^{2} I_{k}}{T^{3}}-\frac{D s I e}{T^{3}}\left[M^{2}-N^{2}(1-\alpha)\right]>0$.

Sub case $2 . \boldsymbol{N} \leq \boldsymbol{T} \leq \boldsymbol{M}$ (See in figure 2$)$

In this case, the account is settled at $T=M$ and retailer does not need to pay any interest charge.

$I C_{2}=0$.

All sells revenue is utilized to earn interest with annual rate $I e$ during the period $(N, M)$

$I E_{2}=\frac{s I e}{T}\left[\int_{0}^{N} \alpha D t d t+\int_{N}^{T} D t d t+D T(M-T)\right]=\frac{D s I e}{2 T}\left[\alpha N^{2}+\left(T^{2}-N^{2}\right)+2 T(M-T)\right]$,

$T R C_{2}=\frac{A}{T}+\frac{D(c \theta+h)}{\theta^{2} T}\left(e^{\theta T}-\theta T-1\right)-\frac{D s I e}{2 T}\left[\alpha N^{2}+\left(T^{2}-N^{2}\right)+2 T(M-T)\right]$.

Similarly, the optimum value of $T=T_{2}$ is the solution of equation. We get 
$\frac{d T R C_{2}(T)}{d T}=-\frac{A}{T^{2}}+\frac{D(c \theta+h)}{2}+\frac{s I e D N^{2}}{2 T^{2}}(1-\alpha)+\frac{D s I e}{2}$,

$T=T_{2}$ minimizes total cost; $T R C_{2}(T)$ provided

$\frac{d^{2} T R C_{2}(T)}{d T^{2}}=\frac{2 A}{T^{3}}-\frac{s I e D N^{2}(1-\alpha)}{T^{3}}>0$.

Sub case $3.0<T \leq N$ (See in figure 3 )

There is no interest payable by retailer because the account is settled at $T=M$, therefore $I C_{3}=0$

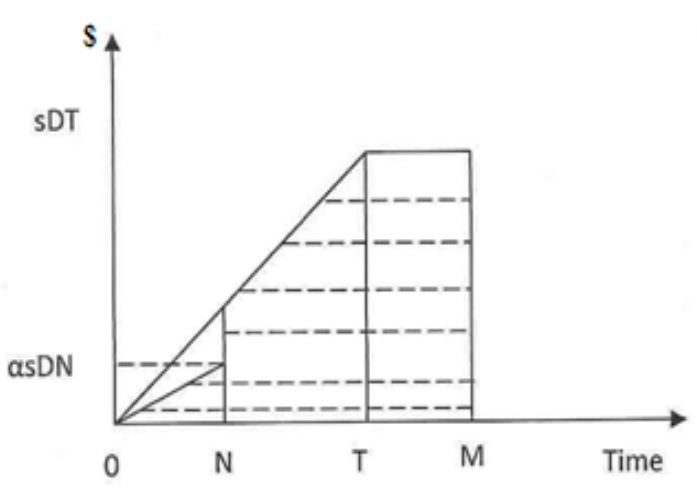

Fig. 2. The total accumulation of interest earned when $N \leq T \leq M$

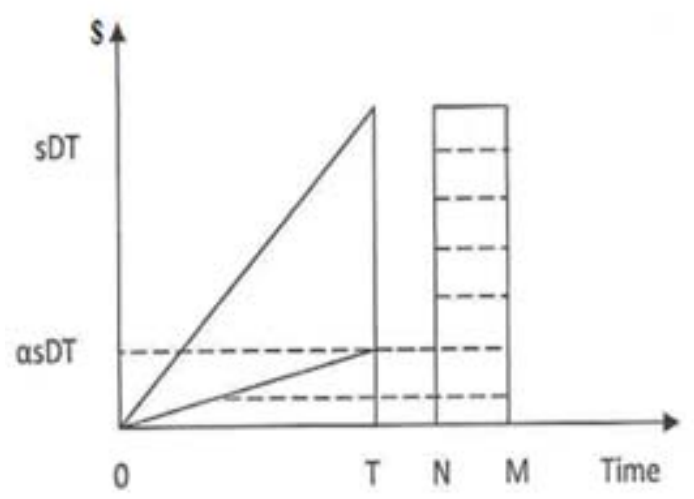

Fig. 3. The total accumulation of interest earned when $T \leq N$

The revenue from the selling goods is utilized to earn interest with annual rate $I e$ during the period $(N, M)$.

$$
\begin{array}{rl}
I E_{3} & =\frac{s I e}{T}\left[\int_{0}^{T} \alpha D t d t+\alpha D T(N-T)+D T(M-N)\right] \\
& =\frac{s I e}{T}\left[\frac{\alpha D T^{2}}{2}+\alpha D T(N-T)+D T(M-N)\right] \\
T R & R C_{3}=\frac{A}{T}+\frac{D(c \theta+h)}{\theta^{2} T}\left(e^{\theta T}-\theta T-1\right)-\frac{s I e}{2 T}\left[\alpha D T^{2}+2 \alpha D T(N-T)+2 D T(M-N)\right] .
\end{array}
$$

Likewise, The optimum value of $T=T_{3}$ is the solution of following equation,

$\frac{d T R C_{3}(T)}{d T}=-\frac{A}{T^{2}}+\frac{D(c \theta+h)}{2}+\frac{\text { DsIe } \alpha}{2}$

$T=T_{3}$ minimizes total cost; $T R C_{3}(T)$ provided

$\frac{d^{2} T R C_{3}(T)}{d T^{2}}=\frac{2 A}{T^{3}}>0$ 
Since $T R C_{1}(M)=T R C_{2}(M)$ and $T R C_{2}(N)=T R C_{3}(N), T R C(T)$ is continuous and well-defined. All $T R C_{1}(T), T R C_{2}(T), T R C_{3}(T)$ and $T R C(T)$ are defined on $T>0$,

Eqs. (17) and (22) imply that $T R C_{2}(T)$ and $T R C_{3}(T)$ are convex on $T>0$ and Eq. (12) implies that $T R C_{1}(T)$ is convex on $T>0$ when $2 A+c D I_{k} M^{2}-D s I e\left[M^{2}-(1-\alpha) N^{2}\right]>$. Furthermore, we have $T R C_{1}^{\prime}(M)=T R C_{2}^{\prime}(M)$ and $T R C_{2}^{\prime}(N)=T R C_{3}^{\prime}(N)$. Therefore, Eqs. (10), (15) and (20) imply that $T R C(T)$ is convex on $T>0$ when $2 A+C D I_{k} M^{2}-D S I e\left[M^{2}-(1-\alpha) N^{2}\right]>0$.

Case 2. $\mathbf{M}<N$

Sub case $4 . M \leq T$ (See in figure 4$)$

In this case, the account is settled at $M$. The item which are still in inventory has to financed with annually rate $I_{k}$ during the period $(M, T)$. Therefore, the annual interest paid is as follows,

$I C_{4}=\frac{c I_{k}}{T} \int_{M}^{T} Q(t) d t=\frac{c D I_{k}}{\theta^{2} T}\left[e^{\theta(T-M)}-\theta(T-M)-1\right]$.

The retailer sells products and deposits the revenue in an interest bearing account at the rate Ie/\$/ year during the period $(0, M)$.

$I E_{4}=\frac{s I e}{T} \int_{0}^{M} \alpha D t d t=\frac{D M^{2} \operatorname{sIe} \alpha}{2 T}$.

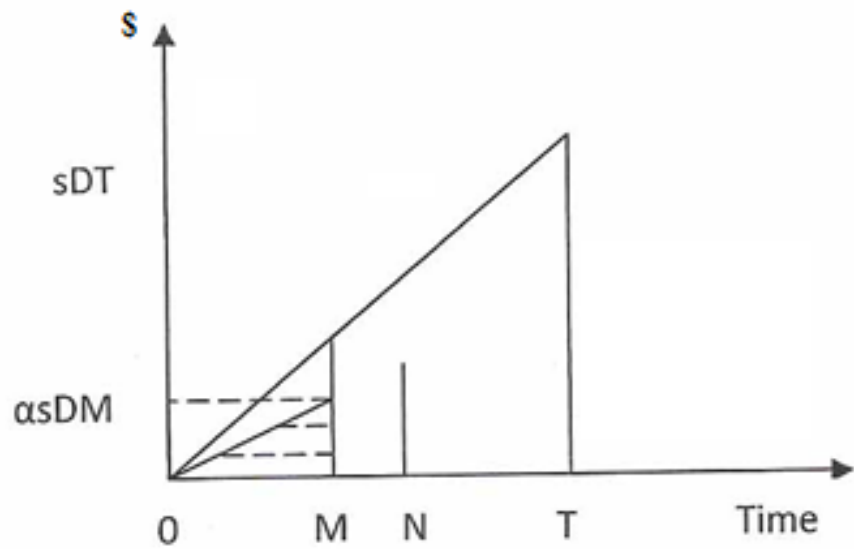

Fig. 4. The total accumulation of interest earned when $M \leq T$

$T R C_{4}=\frac{A}{T}+\frac{D(c \theta+h)}{\theta^{2} T}\left(e^{\theta T}-\theta T-1\right)+\frac{c D I_{k}}{\theta^{2} T}\left[e^{\theta(T-M)}-\theta(T-M)-1\right]-\frac{s I e D M^{2} \alpha}{2 T}$.

Likewise, The optimum value of $T=T_{4}$ is the solution of the following equation

$\frac{d T R C_{4}(T)}{d T}=-\frac{A}{T^{2}}+\frac{D(c \theta+h)}{2}+\frac{c D I_{k}}{2}-\frac{c D M^{2} I_{k}}{2 T^{2}}+\frac{D s I e M^{2} \alpha}{2 T^{2}}$.

$T=T_{4}$ minimizes total cost; $T R C_{4}(T)$ provided

$\frac{d^{2} T R C_{4}(T)}{d T^{2}}=\frac{2 A}{T^{3}}+\frac{c D M^{2} I_{k}}{T^{3}}-\frac{D_{s I e M^{2} \alpha}}{T^{3}}>0$, 
Sub case $5 . T \leq M$ (See in figure 5)

Here, the retailer sells the product during $(0, T)$ and completely settles his/her account to supplier at time $T=M$, so the interest payable is

$I C_{5}=0$.

The retailer sells products during $(0, T)$ and deposits the sales revenue in an interest bearing account at the rate of $I e / \$ /$ year. In the period $(T, M)$ the retailer deposits the total revenue into the account that earn $I e / \$ /$ year, therefore, interest earned per year is

$I E_{5}=\frac{\operatorname{sIe}}{T}\left[\int_{0}^{T} \alpha D t d t+\alpha D T(M-T)\right]=\frac{D \operatorname{sIe} \alpha}{2}[2 M-T]$.

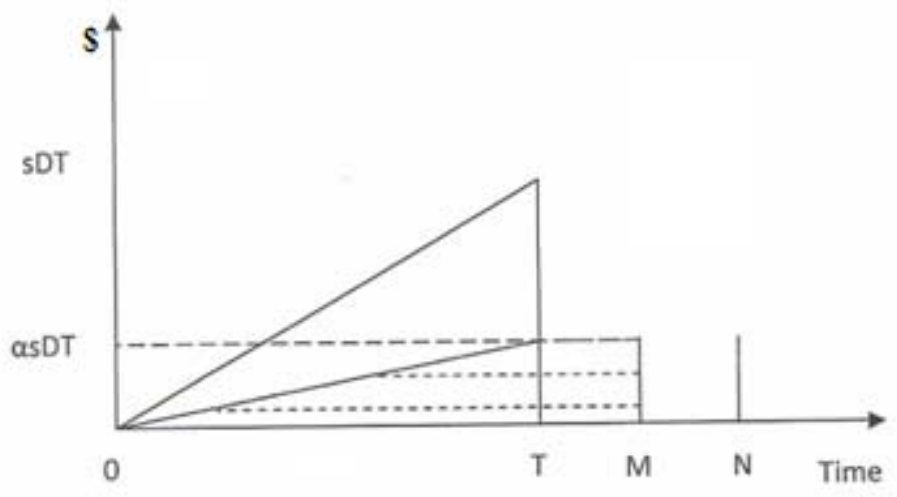

Fig. 5. The total accumulation of interest earned when $T \leq M$

$T R C_{5}=\frac{A}{T}+\frac{D(c \theta+h)}{\theta^{2} T}\left(e^{\theta T}-\theta T-1\right)-\frac{D s I e \alpha}{2}[2 M-T]$.

Likewise, The optimum value of $T=T_{5}$ is the solution of the following equation,

$\frac{d T R C_{5}(T)}{d T}=-\frac{A}{T^{2}}+\frac{D(c \theta+h)}{2}+\frac{D s I e \alpha}{2}$.

$T=T_{5}$ minimizes total cost; $T R C_{5}(T)$ provided

$\frac{d^{2} T R C_{4}(T)}{d T^{2}}=\frac{2 A}{T^{3}}>0$.

Since $T R C_{4}(M)=T R C_{5}(M), T R C(T)$ is continuous and well-defined. All $T R C_{4}(T), T R C_{5}(T)$, and $T R C(T)$ are defined on $T>0$.

Eq. (32) implies that $T R C_{5}(T)$ is continuous on $T>0$ and Eq. (27) implies that $T R C_{4}(T)$ is convex on $T>0$ when $2 A+D M^{2}\left(c I_{k}-s \alpha I e\right)>0$. Furthermore, we have $T R C_{4}^{\prime}(M)=T R C_{5}^{\prime}(M)$. Therefore, Eqs. (25) and (30) imply that $T R C(T)$ is convex on $T>0$ when $2 A+D M^{2}\left(c I_{k}-\right.$ s $\alpha I e)>0$. 


\section{Determination of the optimal cycle time $T^{*}$}

\section{Case 1. $M \geq N$}

The first-order conditions for $T R C_{1}(T), T R C_{2}(T)$ and $T R C_{3}(T)$ in Eqs. (11), (16), (21) is $\frac{d T R C_{1}(T)}{d T}=\frac{d T R C_{2}(T)}{d T}=\frac{d T R C_{3}(T)}{d T}=0$. Thus, the optimal values of $T$ for sub-case $1,2,3$ are

$T_{1}^{*}=\sqrt{\frac{2 A+c D M^{2} I_{k}-s D I e\left[M^{2}-(1-\alpha) N^{2}\right]}{D\left(h+c \theta+c I_{k}\right)}}$,

$2 A+c D M^{2} I_{k}-s D I e\left[M^{2}-(1-\alpha) N^{2}\right]>0$.

$T_{2}^{*}=\sqrt{\frac{2 A+s D(1-\alpha) N^{2} I e}{D(h+c \theta+s I e)}}$,

$T_{3}^{*}=\sqrt{\frac{2 A}{D(h+c \theta+s \alpha I e)}}$.

Eq. (33) gives the optimal value of $T^{*}$ for the case when $T \geq M$ so that $T_{1}^{*} \geq M$, we substitute Eq. (33) into $T_{1}^{*} \geq M$ which yields,

$T_{1}^{*} \geq M$ if and only if $-2 A+D M^{2}(c \theta+h)+s D I e\left[M^{2}-(1-\alpha) N^{2}\right] \leq 0$.

Similarly, Eq. (34) gives the optimal value of $T^{*}$ for the case when $N \leq T \leq M$ so that $N \leq T_{2}^{*} \leq M$. We substitute Eq. (34) into $N \geq T_{2}^{*} \leq M$, and then we obtain that $T_{2}^{*} \leq M$ if and only if

$-2 A+D M^{2}(c \theta+h)+s D I e\left[M^{2}-(1-\alpha) N^{2}\right] \geq 0$,

and $N \leq T_{2}^{*}$ if and only if

$-2 A+D N^{2}(h+c \theta+s \alpha I e) \leq 0$

Finally, Eq. (35) gives the optimal value of $T^{*}$ for the case when $T \leq N$ so that $T_{3}^{*} \leq N$. We substitute Eq. (35) into $T_{3}^{*} \leq N$; then we obtain that $T_{3}^{*} \leq N$ If and only if

$-2 A+D N^{2}(h+c \theta+s \alpha I e) \geq 0$.

Furthermore, we have

$\Delta_{1}=-2 A+D M^{2}(c \theta+h)+s D I e\left[M^{2}-(1-\alpha) N^{2}\right]$,

and

$\Delta_{2}=-2 A+D N^{2}(h+c \theta+s \alpha I e)$.

Eqs. (36) and (37) imply that $\Delta_{1} \geq \Delta_{2}$. From the above arguments, we obtain the following results

\section{Theorem 1.}

(A) If $\Delta_{2} \geq 0$, then $\operatorname{TRC}\left(T^{*}\right)=\operatorname{TRC}\left(T_{3}^{*}\right)$ and $T^{*}=T_{3}^{*}$.

(B) If $\Delta_{1}>0$ and $\Delta_{2}<0$, then $\operatorname{TRC}\left(T^{*}\right)=\operatorname{TRC}\left(T_{2}^{*}\right)$ and $T^{*}=T_{2}^{*}$.

(C) If $\Delta_{1} \leq 0$, then $\operatorname{TRC}\left(T^{*}\right)=\operatorname{TRC}\left(T_{1}^{*}\right)$ and $T^{*}=T_{1}^{*}$. 
Case 2. $\mathbf{M}<N$

The first-order conditions for $T R C_{4}(T), T R C_{5}(T)$ in Eqs. (26), (31) to be minimized is $\frac{d T R C_{4}(T)}{d T}=$ $\frac{d T R C_{5}(T)}{d T}=0$. Thus, the optimal values of $T$ for sub-case 4,5 are

$T_{4}^{*}=\sqrt{\frac{2 A+D M^{2}\left(c I_{k}-s \alpha I e\right)}{D\left(h+c \theta+c I_{k}\right)}}$.

If

$2 A+D M^{2}\left(C I_{k}-S \alpha I e\right)>0$

And

$T_{5}^{*}=\sqrt{\frac{2 A}{D(h+c \theta+\operatorname{sIe} \alpha)}}$.

Eq. (38) gives the optimal value of $T^{*}$ for the case when $T \geq M$ so that $T_{4}^{*} \geq M$. We substitute Eq. (38) into $T_{4}^{*} \geq M$; then we obtain that

$T_{4}^{*} \geq M$ If and only if

$-2 A+D M^{2}(h+c \theta+\operatorname{sIe} \alpha) \leq 0$.

Similarly, Eq. (39) gives the optimal value of $T^{*}$ for the case when $T \leq M$ so that $T_{5}^{*} \leq M$. We substitute Eq. (39) into $T_{5}^{*} \leq M$; which yields,

$T_{5}^{*} \leq M$ If and only if

$-2 A+D M^{2}(h+c \theta+s \alpha I e) \geq 0$.

Furthermore, we let

$\Delta_{3}=-2 A+D M^{2}(h+c \theta+\operatorname{sIe} \alpha)$.

From the above arguments, we can obtain the following results.

\section{Theorem 2.}

(A) If $\Delta_{3} \geq 0$, thenTRC $\left(T^{*}\right)=\operatorname{TRC}\left(T_{5}^{*}\right)$ and $T^{*}=T_{5}^{*}$.

(B) If $\Delta_{3}<0$, then $\operatorname{TRC}\left(T^{*}\right)=\operatorname{TRC}\left(T_{4}^{*}\right)$ and $T^{*}=T_{4}^{*}$.

\section{Special cases}

\section{Huang's and Hsu's Model}

When $\theta=0$, ie. Deteriorating items is not considered then Eqs. (33), (34), (35). (38), (39) become as follows

$=\sqrt{\frac{T_{6}^{*}}{D\left(h+c D M^{2} I_{k}-s D I e\left[M^{2}-(1-\alpha) N^{2}\right]\right.}}$, 


$$
\begin{aligned}
& T_{7}^{*}=\sqrt{\frac{2 A+s D(1-\alpha) N^{2}}{D(h+s I e)}}, \\
& T_{8}^{*}=\sqrt{\frac{2 A}{D(h+s \alpha I e)}} \\
& T_{9}^{*}=\sqrt{\frac{2 A+D M^{2}\left(c I_{k}-s \alpha I e\right)}{D\left(h+c I_{k}\right)}} \\
& T_{10}^{*}=\sqrt{\frac{2 A}{D\left(h+c I_{k}\right)}} .
\end{aligned}
$$

\section{Huang's Model}

When $M \geq N, s=c$, and $\alpha=0$ then Eqs. (41), (42) and (43) become as follows

$T_{11}^{*}=\sqrt{\frac{2 A+c D\left[M^{2}\left(I_{k}-I e\right)+N^{2} I e\right]}{D\left(h+c I_{k}\right)}}$,

$T_{12}^{*}=\sqrt{\frac{2 A+c D N^{2} I e}{D(h+c I e)}}$,

$T_{13}^{*}=\sqrt{\frac{2 A}{D h}}$.

\section{Goyal's Model}

When $N=0$ Eqs. (46) and (47) become as follows

$T_{14}^{*}=\sqrt{\frac{2 A+c D M^{2}\left(I_{k}-I e\right)}{D\left(h+c I_{k}\right)}}$,

$T_{15}^{*}=\sqrt{\frac{2 A}{D(h+c I e)}}$.

\section{Numerical examples}

Optimal Solution when $M \geq N$

$D=1200$ Units/year, $c=\$ 8 /$ units, $h=\$ 5 /$ unit/year, $I_{k}=\$ .14 /$ year, $I e=\$ .11 /$ year, $M=$ .12year,

$s=\$ 15 /$ Unit, $\theta=0.01, N=0.07$ year, $A=\$ 60 /$ order 


\section{Table 1}

The effect of customer's fraction of total amount owed payable at the time of placing an order offered by the retailer on decision policy

\begin{tabular}{lccc}
\hline$\alpha$ & $\mathrm{T}$ & $\mathrm{Q}$ & $\mathrm{TRC}$ \\
\hline 0.2 & 0.1263 & 151.66 & 778.28 \\
0.4 & 0.1252 & 150.33 & 770.45 \\
0.6 & 0.1242 & 149.13 & 762.95 \\
0.8 & 0.1231 & 147.31 & 754.85 \\
\hline
\end{tabular}

As we can observe, as $\alpha$ increases cycle time, order quantity and total cost decreases.

Therefore, the retailer will order less quantity and increase the order frequency. The retailer can accumulate more interest under higher order frequency.

$s=\$ 15 /$ Unit, $\theta=0.01, \alpha=0.2, A=\$ 60 /$ order

\section{Table 2}

The effect of customer's trade credit period offered by the retailer on decision policy

\begin{tabular}{lccc}
\hline $\mathrm{N}$ & $\mathrm{T}$ & $\mathrm{Q}$ & $\mathrm{TRC}$ \\
\hline 0.07 & 0.1263 & 151.66 & 778.28 \\
0.08 & 0.1275 & 153.10 & 787.56 \\
0.09 & 0.1289 & 154.78 & 798.07 \\
0.10 & 0.1305 & 156.70 & 809.83 \\
\hline
\end{tabular}

As $N$ is increased, order quantity, cycle time and total cost also increase. The retailer will order more quantity to accumulate more interest to compensate the loss of interest earned.

$N=0.07$ Year, $\theta=0.01, \alpha=0.2, A=\$ 60 /$ order

\section{Table 3}

The effect of selling price on decision policy

\begin{tabular}{lccc}
\hline $\mathrm{S}$ & $\mathrm{T}$ & $\mathrm{Q}$ & $\mathrm{TRC}$ \\
\hline 15 & 0.1263 & 151.66 & 778.28 \\
25 & 0.1189 & 142.76 & 721.18 \\
40 & 0.1112 & 133.51 & 632.76 \\
50 & 0.1072 & 128.71 & 569.36 \\
\hline
\end{tabular}

Cycle time and order quantity decreases but total cost increase when $s$ increases. The retailer will order less quantity to take the benefits of trade credit, more frequently.

$N=0.07$ Year, $s=15 /$ units, $\alpha=0.2, A=\$ 60 /$ order

\section{Table 4}

The effect of deteriorating items on decision policy

\begin{tabular}{lccc}
\hline$\theta$ & $\mathrm{T}$ & $\mathrm{Q}$ & $\mathrm{TRC}$ \\
\hline 0.01 & 0.1263 & 151.66 & 778.28 \\
0.02 & 0.1255 & 150.79 & 784.49 \\
0.03 & 0.1247 & 149.92 & 790.60 \\
0.04 & 0.1239 & 179.05 & 796.73 \\
\hline
\end{tabular}


As deterioration increases optimal cycle time and order quantity decreases but total cost increases. Increase in deterioration rate forces retailer to buy more number of units frequently.

$N=0.07$ Year, $s=15 /$ units, $\alpha=0.2, \theta=0.01$

\section{Table 5}

The effect of ordering cost on decision policy

\begin{tabular}{lccc}
\hline A & T & Q & TRC \\
\hline 40 & 0.1042 & 125.11 & 604.83 \\
50 & 0.1152 & 136.68 & 695.11 \\
60 & 0.1263 & 151.66 & 778.28 \\
70 & 0.1365 & 163.91 & 854.42 \\
\hline
\end{tabular}

With increase of ordering cost cycle time, order quantity and total cost increases. Increases of ordering cost forces retailer to buy less quantity frequently and increase total cost of an inventory system.

Optimal solutions when $M<N$

$D=4000$ Units/year, $c=\$ 8 /$ units, $h=\$ 7 /$ unit/year, $I_{k}=\$ .09 / \$ /$ year, Ie $=\$ .12 / \$ /$ year, $M=.06$ year,

$A=\$ 60 / 0 \mathrm{rder}, s=15 /$ units, $\theta=0.01$

Table 6.

The effect of customer's fraction of total amount owed payable at the time of placing an order offered by the retailer on decision policy

\begin{tabular}{lccc}
\hline$\alpha$ & $\mathrm{T}$ & $\mathrm{Q}$ & TRC \\
\hline 0.2 & 0.0633 & 253.28 & 1802.17 \\
0.4 & 0.0620 & 248.08 & 1761.14 \\
0.6 & 0.0607 & 242.87 & 1718.82 \\
0.8 & 0.0593 & 237.27 & 1677.51 \\
\hline
\end{tabular}

As $\alpha$ increases cycle time, order quantity and total cost decreases. Therefore, the retailer will order less quantity and increase the order frequency. The retailer can accumulate more interest under higher order frequency. $A=\$ 60 / 0 \operatorname{rder}, \alpha=0.01, \theta=0.01$

\section{Table 7}

The effect of selling price on decision policy

\begin{tabular}{lccc}
\hline $\mathrm{S}$ & $\mathrm{T}$ & $\mathrm{Q}$ & $\mathrm{TRC}$ \\
\hline 15 & 0.0633 & 253.28 & 1802.17 \\
25 & 0.0625 & 250.08 & 1774.46 \\
40 & 0.0611 & 244.47 & 1735.62 \\
50 & 0.0602 & 240.87 & 1704.64 \\
\hline
\end{tabular}

Cycle time and order quantity decreases but total cost increase when $s$ increases. The retailer will order less quantity to take the benefits of trade credit more frequently.

$A=\$ 60 /$ order $, \alpha=0.01, s=\$ 15 /$ year

\section{Table 8}

The effect of deteriorating items on decision policy

\begin{tabular}{llll}
\hline$\theta$ & $\mathrm{T}$ & $\mathrm{Q}$ & TRC \\
\hline 0.01 & 0.0633 & 253.28 & 1802.17 \\
0.02 & 0.0630 & 252.16 & 1813.86 \\
0.03 & 0.0627 & 251.04 & 1824.12 \\
0.04 & 0.0624 & 249.91 & 1834.55 \\
\hline
\end{tabular}


As deterioration increases optimal cycle time and order quantity decreases but total cost increases. An increase in deterioration rate forces retailer to buy more number of units, frequently.

$\theta=0.01, \alpha=0.01, s=\$ 15 /$ year

Table 9

The effect of ordering cost on decision policy

\begin{tabular}{llll}
\hline $\mathrm{A}$ & $\mathrm{T}$ & $\mathrm{Q}$ & $\mathrm{TRC}$ \\
\hline 40 & 0.0518 & 207.25 & 1455.70 \\
50 & 0.0580 & 232.07 & 1637.73 \\
60 & 0.0633 & 253.28 & 1802.17 \\
70 & 0.0682 & 272.89 & 1957.18 \\
\hline
\end{tabular}

With the increase on ordering cost cycle time, order quantity and total cost increases. The increase on ordering cost forces retailer to buy less quantity frequently and increase the total cost of an inventory system.

\section{Conclusions}

In this paper, we have investigated the retailer's optimal inventory policy with two levels of trade credit and deteriorating items in supply chain coordination. The retailer's optimal inventory policy is derived when supplier offers a full trade credit to retailer but retailer offers partial trade credit to his/her customer with constant rate of deterioration. The closed form solution is obtained by using Taylor series expansion. The implementation of the proposed model has been demonstrated using some numerical examples and they are analyzed.

\section{References}

Abdul, I. \& Murata, A., (2011). An inventory model for deteriorating items with varying demand pattern and unknown time horizon. International Journal of Industrial Engineering Computations 2, 61-86.

Aggarwal, S. P. (1978). A note on an order level inventory model for a system with constant rate of deterioration. Opsearch 15, 184-187.

Aggrawal, S.P., \& Jaggi, C.K. (1995). Ordering policies of deteriorating items under permissible delay in payments. Journal of the Operational Research Society, 46, 658-662.

Chang, C. T., (2002). Extended economic order quantity model under cash discount and payment delay. International Journal of Information and Management Science, 13, 57-69.

Chang, K. J., \& Liao, J. J. (2006). The optimal ordering policy in a DCF analysis for deteriorating items when trade credit depends on the order quantity. Journal of Production Economics, 100, 116-130.

Chen, M. S., \& Chuang, C. C. (1999). An analysis of light buyer's economic order model under trade credit. Asia-Pacific Journal of Operational Research, 16, 23-24.

Chu, P., Chung K. J. \& Lan, S. P. (1998). Economic order quantity of deteriorating items under permissible delay in payments. Computers and Operations Research, 25, 817-824.

Chung, H. J., \& Dye, C. Y. (2001). An inventory model for deteriorating items with partial backlogging and permissible delay in payments. International Journal of system Science, 32, 345352.

Chung, H. J., \& Dye, C. Y. (2002). An inventory model for deteriorating items under the condition of permissible delay in payments. Yugoslav Journal of Operational Research, 1, 73-84.

Chung, H. J., Huang, C. H. \& Dye, C. Y. (2001). An inventory model for deteriorating items with linear trend demand under the condition of permissible delay in payments. Production Planning and Control, 12, 274-282. 
Chung, K. J. (1998a). A theorem on the determination of economic orders quantity under condition of permissible delay in payments. Computers \& Operations Research, 25, 49-52.

Chung, K. J. (2000). The inventory replenishment policy for deteriorating items under permissible delay in payments. Opsearch, 37, 267-281.

Chung, K. J. \& Huang, Y. F. (2003). The optimal cycle time for EPQ inventory model under permissible delay in payments. International Journal of Production Economics, 84, 307-318.

Chung, K. J. \& Liao, J. J. (2004). Lot-sizing decisions under trade credit depending on the order quantity. Computers \& Operations Research, 3, 909-928.

Chung, K. J., (1998b) Economic order quantity model when delay in payments is permissible. Journal of Information and Optimization Science, 19, 411-416.

Chung, K. J., Goyal, S. K., \& Huang, Y. F. (2005). The Optimal inventory policies under permissible delay in payments depending on the ordering quantity. International Journal of Production Economics, 95, 303-213.

Covert, R. B. \& Philip, G. S. (1973). An EOQ model with weibull distribution deterioration. AIIE Trans, 5, 323-326.

Dave, U. \& Patel, L. K. (1981). (T, Si) Policy inventory model for deteriorating items with time proportional demand. Journal of Operational Research Society, 32, 137-142.

Ghare, P. M. \& Schrader, G. P., (1963). A model for an exponentially decaying inventory. Journal of Industrial Engineering, 14, 238-243.

Giri, B. C. \& Chakraborty, A. (2010). Supply chain coordination for a deteriorating product under stock-dependent consumption and unreliable production process. International Journal of Industrial Engineering Computations, 2(1), 179-192.

Hariga, M. A. (1996). Optimal EOQ models for deteriorating items with time-varying demand Journal of Operational Society, 47, 1228-1246.

Huang, Y. F., \& Chung K. J., (2003). Optimal replenishment policies in the EOQ model under cash discount and trade credit, Asia-Pacific Journal of Operational Research, 20, 177-190.

Huang, Y. F. \& Hsu, K. H. (2008) An EOQ model under retailer partial trade credit policy in supply chain. International Journal of Production Economics, 112, 655-664.

Huang, Y. F. (2007). Economic order quantity under conditionally permissible delay in Payments. European Journal of Operational Research, 176, 911-924.

Hwang, H. \& Shinn, S.W. (1997). Retailers pricing and lot sizing policy for exponentially deterioration products under the conditions of permissible delay in payments. Computers \& Operation Research, 24, 539-547.

Jaggi, C.K., Goel, S.K. \& Mittal, M. (2011). Economic order quantity model for deteriorating items with imperfect quality and permissible delay in payment. International Journal of Industrial Engineering Computations, 2(1), 123-140.

Jamal, A. M. M., Sarker, B. R. \& Wang, S. (1997). An ordering policy for deteriorating items with allowable shortages and permissible delay in payment. Journal of the Operational Research Society, 48, 826-833.

Jamal, A. M. M., Sarker, B.R. \& Wang, S. (2000) Optimal payment time for a retailer under permitted delay of payment by the wholesaler. International Journal of Production Economics, 66, 59-66.

Liao, H.C., Tsai C.H. \& Su, C. T. (2000). An inventory model with deteriorating items under inflation when a delay in payment permissible. International Journal of Production Economics, 63, 207-214.

Liao, J. J. \& Chung, K.J. (2009). An EOQ model for deterioration items under trade credit policy in a supply chain system. Journal of Operation Research Society of Japan, 52, 46-57.

Mondal, B. N., Phaujdar, S. (1989b). An inventory model for deteriorating items and stock-dependent consumption rate. Journal of Operational Research Society, 40, 483-488.

Mondal, B.N., \& Phaujdar, S. (1989c). Some EOQ models under permissible delay in payments. International Journal of Management Science, 5, 99-108. 
Ouyang, L.Y., Chang, C.T. \& Teng, J.T. (2005). An EOQ model for deteriorating items under trade credits. Journal of Operational Research Society, 56, 719-726.

Sachan, R, S. (1984). On (T, Si) policy inventory model for deteriorating items with time proportional demand. Journal of Operational Research Society, 35, 1013-1019.

Salameh, M. K., Abbound, N. E., Ei-Kassar, A. N. \& Ghattas, R. E. (2003). Continuous review inventory model with delay in payment. International Journal of Production Economics, 85, 9195.

Sarker, B. R., Jamal, A. M. M. \& Wang, S. (2000). Supply chain model perishable products under inflation and permissible delay in payment. Computers \& Operations Research, 27, 59-75.

Sarker, B. R., Jamal, A. M. M. \& Wang, S. (2001). Optimal payment time under permissible delay in payment for product with deteriorating. production Planning and Control, 11, 380-390.

Shah, N. H. (1993a). Probabilistic time-scheduling model for an exponentially decaying inventory when delay in payments is permissible. International Journal of Production Economics, 32, 77 82.

Shah, N. H. (1993b). A lot size model for exponentially decaying inventory when delay in payment is permissible. Cahiers du CERO, 35, 115-123.

Shah, N. H. \& Mishra, P. (2010). An EOQ model for deteriorating items under supplier credits when demand is stock-dependent. Yugoslav Journal of Operations Research, 20, 1 145-156.

Shah, V. R., Patel, N. C. \& Shah, D. K. (1988). Economic ordering quantity when delay in payments of order and shortages are permitted. Gujarat Statistical Review, 15(2) 52-56.

Shah, V. R., Sreehari, M. (1996). An inventory model for a system with multiple storage facility. Opsearch, 33, (2) 96-106.

Shah, Y. K. \& Jaiswal M. C. (1977). An order level inventory model for a system with constant rate of deterioration. Opsearch, 14, 174-184.

Teng, J. T. \& Yang, H. L. (2004). Deterministic Economic Order Quantity models with partial backlogging when demand and cost are fluctuating with time. Journal of Operational Research Society, 55, 495-503.

Teng, J. T., Chern, M. S., Yang, H. L. \& Wang, Y. J. (1999). Deterministic lot size inventory models with shortages and deterioration for fluctuating demand. Naval Research Logistic, 24, 65-72.

Yang, H. L, Teng, J. T. \& Chern, M. S. (2001). Deterministic inventory lot-size models under inflation with shortages and deterioration for fluctuating demand. Naval Research Logistic,48, 144-158.

Yang, H. L., Teng, J. T. \& Chern, M. S. (2010). An inventory model under inflation for deteriorating items with stock-dependent consumption rate and partial backlogging shortages. International Journal of Production Economics, 123, 8-19. 